\title{
Exploring Interactions Between Fruit and Vegetable Production in a Greenhouse and an Anaerobic Digestion Plant-Environmental Implications
}

\author{
Daniel Danevad $^{\star \dagger}$ and Sandra Carlos-Pinedo ${ }^{\dagger}$ \\ Department of Building Engineering, Energy Systems and Sustainability Science, University of Gävle, Gävle, Sweden
}

Greenhouse fruit and vegetable production uses large amounts of energy and other resources, and finding ways of reducing its impact may increase sustainability. Outputs generated from solid-state anaerobic digestion (SS-AD) are suitable for use in

OPEN ACCESS

Edited by:

Paul Jensen,

Hull City Council, United Kingdom

Reviewed by:

Spyridoula Gerassimidou,

University of Leeds, United Kingdom

Hirra Anjum,

University of Engineering and

Technology, Pakistan

*Correspondence:

Daniel Danevad

daljon@hig.se

tThese authors have contributed equally to this work and share first authorship

\footnotetext{
Specialty section:

This article was submitted to

Circular Economy,

a section of the journal

Frontiers in Sustainability
}

Received: 03 September 2021 Accepted: 06 December 2021 Published: 22 December 2021

Citation:

Danevad D and Carlos-Pinedo S (2021) Exploring Interactions Between

Fruit and Vegetable Production in a

Greenhouse and an Anaerobic

Digestion Plant-Environmental

Implications.

Front. Sustain. 2:770296.

doi: 10.3389/frsus.2021.770296 greenhouses, which creates a need to investigate the consequences of the possible interactions between them. Connecting the fruit and vegetable production with the resource flows from an SS-AD process, e.g., biogas and digestate, could increase circularity while decreasing the total environmental impact. There are currently no studies where a comprehensive assessment of the material flows between greenhouses and SS-AD are analyzed in combination with evaluation of the environmental impact. In this study, material flow analysis is used to evaluate the effects of adding tomato related waste to the SS-AD, while also using life cycle assessment to study the environmental impact of the system, including production of tomatoes in a greenhouse and the interactions with the SS-AD. The results show that the environmental impact decreases for all evaluated impact categories as compared to a reference greenhouse that used inputs and outputs usually applied in a Swedish context. Using the tomato related waste as a feedstock for SS-AD caused a decrease of biomethane and an increase of carbon dioxide and digestate per ton of treated waste, compared to the digestion of mainly food waste. In conclusion, interactions between a greenhouse and an SS-AD plant can lead to better environmental performance by replacing some of the fertilizer and energy required by the greenhouse.

Keywords: hydroponic process, greenhouse, life cycle assessment, industrial symbiosis, digestate, tomato, anaerobic digestion (AD)

\section{INTRODUCTION}

Research has shown that the anthropogenic emissions of carbon dioxide $\left(\mathrm{CO}_{2}\right)$ have to decrease by $45 \%$ by 2030 , as well as reaching net zero around 2050 , to have the possibility of containing the global warming below $1.5^{\circ} \mathrm{C}$ (IPCC, 2018). Human food consumption is currently responsible for $26 \%$ of the anthropogenic contribution to climate change (Poore and Nemecek, 2018). Meanwhile, the world population is steadily increasing, which means that behavioral changes and innovation will be required to diminish the increasing environmental impact that is otherwise expected. 
The use of greenhouses is common to produce high amounts of product in a limited space, as well as to produce plants that would not grow well in the surrounding environment. On the other hand, greenhouses can be resource-intensive with high inputs of fuels, nutrients and growing media, especially if they are heated and/or use supplemental lighting. Fossil fuels such as oil and natural gas have traditionally been used to provide energy to greenhouses (Arizpe et al., 2011). Possible negative impacts on the environment include emissions to air and water, land use, and waste from the operation. Plastic and plant residues are other problems related to greenhouse horticulture. The resourceintensive activities of this sector have increased the search for alternative ways in renewable input resources (Menardo et al., 2013).

Sweden is a country that is currently very reliant on imports for many fruits, vegetables, and other crops (Jordbruksverket, 2020). For that reason, it is interesting to evaluate different options of increasing domestic production that would benefit food security. This increase needs to come from systems with high environmental performance, if we want to decrease the environmental impact from food production. Many greenhouse growers in Sweden have already moved away from fossil fuels, although heating with fossil fuels still exists to some extent (Jordbruksverket, 2018). However, there are still opportunities for improved resource efficiency and synergies with the surrounding society. One way of achieving this is through circular economy practices such as industrial symbiosis (Neves et al., 2020). Industrial symbiosis relationships have been fostered through several factors, such as saving resources, obtaining economic benefits, meeting environmental requirements such as reducing greenhouse gas emissions and scarcity of natural resources. By integrating technologies along with the current growth of food crops, it could be the potential driver to a circular economy (Venkata Sreeharsha and Venkata Mohan, 2021). The industrial symbiosis can have other benefits such as waste minimization and waste recycling that would otherwise stop at landfills and incinerators.

Previous studies have evaluated the environmental performance for separated parts of the greenhouse (Dorais and Dubé, 2011; Wallin, 2020), while some others evaluated factors such as the use of residual flows from anaerobic digestion (AD) for food production, specifically, the digestate as nutrient solutions (Botheju et al., 2010; Martin et al., 2019; Bergstrand et al., 2020). AD can also offer other resources for food production systems apart from the digestate, for example, the raw biogas can enter a combined heat and power (CHP) plant to generate electricity and heat. Moreover, if it is separated from the raw biogas, the $\mathrm{CO}_{2}$ flow can be used to increase plant growth.

The use of biogas in Sweden has increased over the years, being over four TWh by 2020. National production was $2.2 \mathrm{TWh}$, where most of the biogas was upgraded for use mainly as vehicle gas. Simultaneously, three million tons of nutrient-rich digestate were produced, of which $87 \%$ was used as fertilizer in agriculture (Energigas Sverige, 2021). Most of the biogas is produced in socalled co-digestion plants that use a mixture of different raw materials, such as food waste, manure, and waste from the food industry. Depending on the nature of the raw materials, the digestion can be wet or liquid (having $<15 \%$ of total solids-TS), L-AD, and dry or solid (having more than 15\% TS), SS-AD (Yang et al., 2015). Waste from greenhouses can be diverse, however, treating only the leaves and branches could be a good feedstock for an SS-AD plant since it is generally fibrous, dry, and could give structure to the waste matrix inside the digester. Connecting both systems, greenhouses and digestion plants, could increase circularity where organic waste from the greenhouse is treated with SS-AD and some of the nutrients are returned to the greenhouse through use of digestate fertilizer. Even if some studies have analyzed different $\mathrm{AD}$ flows that can be connected to greenhouses (Menardo et al., 2013; Stoknes et al., 2016; Burg et al., 2021), to the authors' knowledge there is no literature that covers different flow connections along with detailed study of material flow analysis (MFA) and life cycle assessment (LCA). This study aims to fill a part of this gap by using MFA and LCA to evaluate changes in the potential environmental impact of the possible interactions between an SS-AD plant and a hydroponic greenhouse growing tomatoes. The use of the products from the digestion process, i.e., biogas, digestate, and $\mathrm{CO}_{2}$ as inputs in the greenhouse will be assessed. In turn, the use of tomatorelated waste as an additional feedstock in the SS-AD plant will be evaluated using MFA. The results are also compared to if the same greenhouse had instead used other inputs and outputs that are common in a Swedish context. Advantages of using the MFA method are to create a comprehensive measurement of the content input and output flows for a specific system, which in turn can be used as a base for LCA calculations. This interaction between the methods can be utilized to analyze the environmental performance of prospective production systems before they are created, to ensure that the desired environmental outcome is reached.

\section{MATERIALS AND METHODS}

MFA is a method for accounting the input and output material flows of a system measured in mass units (Sendra et al., 2007). The ORWARE model is a tool for the environmental evaluation of waste management technologies such as $\mathrm{AD}$, incineration, landfilling, among others, that uses the MFA methodology to predict the products, energy balance and emissions of different waste technologies (Eriksson et al., 2002). LCA is a tool that can be used for comparative assessments, either between different systems providing similar functions or between different development stages of a system in an improvement analysis. For this study, the adapted ORWARE model (Carlos-Pinedo et al., 2020) was used to describe the flow balances in the SS$\mathrm{AD}$ process. At this time, ORWARE does not have the capability to do an LCA for food production. Therefore, to assess the environmental impact, information from ORWARE was used together with greenhouse data to create a LCA model in SimaPro using the EcoInvent 3.6 database (Wernet et al., 2016). This research was conducted by using information from literature, databases, and greenhouse organization data, and synthesized the information to create a system that could be analyzed with the described methods. 


\section{Analyzed Objects}

This study has a reference system that consists of a hydroponic greenhouse and various choices of inputs and outputs that are common in a Swedish context. The combined system consists of the same greenhouse where its resource and waste flows have been connected to a local SS-AD plant. The systems are described in detail in section Life Cycle Inventory.

The hydroponic greenhouse used in this study, was based on a model created in the Dutch simulation software SIOM (Systems Integration for International Greenhouse Horticulture). The software was developed by the research organization TNO (the Netherlands Organization for applied scientific research) and is used to simulate and optimize greenhouse cultivation (TNO, 2021). The greenhouse model was developed in a study comparing domestic Swedish production with imports (Danevad et al., 2021) and is used as an example of a high-performing Swedish greenhouse. In this study, only data about energy requirements and levels of $\mathrm{CO}_{2}$ supplementation are included from the SIOM model.

The SS-AD process was based on a plant operating in Forsbacka, Gävle, Sweden. At this time, the plant co-digests biowaste (mainly food waste), green/garden waste, and small portions of horse manure, food slurry, slaughterhouse waste, and structural material such as woody waste. More information about the process and energy use can be found in Carlos-Pinedo et al. (2020). The main products are biogas that is upgraded in the same facility, and the digestate, which is separated into its liquid and solid fractions. In this study, it was assumed that $\mathrm{CO}_{2}$ is captured during the biogas upgrading process. The biogas that is intended for energy production at the greenhouse will not go through the biogas upgrading process, instead, it will be used directly in a $\mathrm{CHP}$ plant at the greenhouse site.

\section{Material Flow Analysis}

The feedstock types and amounts used for the current operation of the SS-AD plant are presented in Table 1. In the combined system, the tomato-related waste (TRW) was then added to the SS-AD process (SS-AD w/TRW) to analyze the impacts of the TRW on the biogas and digestate quantity and quality. The chemical characteristics for the used feedstocks were taken from the ORWARE dataset and are presented in the Supplementary Material. In this study, the TRW was classified as a green waste, as only the leaves were included in the analysis.

\section{Life Cycle Assessment}

\section{Goal and Scope Definition}

The objective of this comparative LCA is to calculate the environmental impact for two different scenarios of Swedish tomato production. The first scenario is the reference system and the second scenario is the combined system where the resource and waste flows of the greenhouse are connected to a local SS-AD plant. The LCA uses the attributional modeling principle.

Although there are several products and by-products within the system, the focus of the study is to evaluate the environmental impact of the tomato production. The functional unit (FU) of this study is therefore $1 \mathrm{~kg}$ of fresh bulk tomato at the greenhouse gate.
TABLE 1 | Feedstock types and amounts in different analyzed setups.

\begin{tabular}{|c|c|c|}
\hline \multirow[t]{2}{*}{ Feedstocks } & Current SS-AD & SS-AD w/TRW \\
\hline & \multicolumn{2}{|c|}{ (t/year) } \\
\hline Biowaste & \multicolumn{2}{|c|}{15,000} \\
\hline Green waste & \multicolumn{2}{|c|}{2,200} \\
\hline Structural material & \multicolumn{2}{|c|}{2,300} \\
\hline Horse manure & \multicolumn{2}{|c|}{670} \\
\hline Wood chips as bedding & \multicolumn{2}{|c|}{330} \\
\hline Food slurry & \multicolumn{2}{|c|}{200} \\
\hline Slaughterhouse waste & \multicolumn{2}{|c|}{50} \\
\hline TRW & - & 340 \\
\hline Total waste & 20,750 & 21,090 \\
\hline
\end{tabular}

TABLE 2 | Main differences between reference system and the combined system.

\begin{tabular}{lll}
\hline Parameter & Reference system & Combined system \\
\hline Heat & Wood chips & $\begin{array}{l}\text { CHP of biogas from } \\
\text { SS-AD }\end{array}$ \\
Electricity & Electrical grid & $\begin{array}{l}\text { Biogas CHP when } \\
\text { possible. Electrical grid } \\
\text { as a supplement. }\end{array}$ \\
Fertilizers & Conventional fertilizer & $\begin{array}{l}\text { Biofertilizer from liquid } \\
\text { digestate. Additional } \\
\text { nutrients from }\end{array}$ \\
& & $\begin{array}{l}\text { conventional fertilizers. } \\
\text { Liquid } \mathrm{CO}_{2} \text { from SS-AD }\end{array}$ \\
Carbon dioxide source & Liquid $\mathrm{CO}_{2}$ from & Digestion in the SS-AD \\
Treatment of organic waste & Composting &
\end{tabular}

The reference system and the combined system have some differences when it comes to inputs and outputs. The main differences are described in Table 2 and both systems can be seen in Figure 1. The organic waste that is generated at the end of the growing season was not included in the assessment as it can contain material that is not suitable for anaerobic digestion (Gävle Energi, 2018). Any damaged fruit generated during the growing season are also excluded, due to lack of data.

\section{Life Cycle Inventory}

The systems and the data acquisition will be described in this section. The data generated in the ORWARE and SIOM models are combined with information from EcoInvent to provide environmental information about the product systems. Additional information about the specific EcoInvent datasets that were used in the study can be found in the Supplementary Material.

The greenhouse model created in the SIOM software was a two hectare Venlo-type glass-covered greenhouse using LED lamps for supplemental lighting. The LED lighting had a capacity of $60 \mu \mathrm{mol} /\left(\mathrm{m}^{2} \cdot \mathrm{s}\right)$ and it was active for a maximum of $12 \mathrm{~h}$ per day, between 7 a.m. and 7 p.m., depending on the need for supplemental lighting. The growing season was assumed to last for 50 weeks starting from the middle of September each 


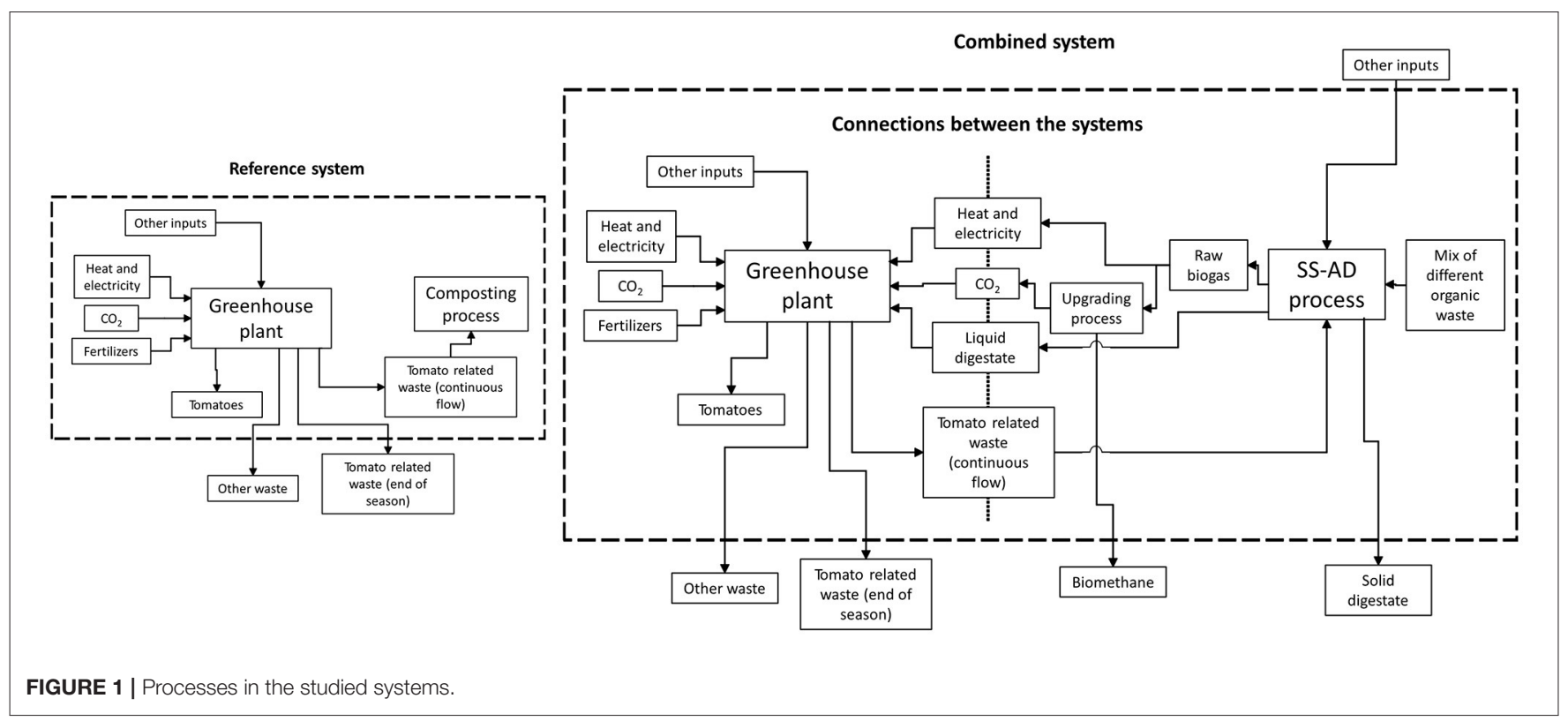

year, and the greenhouse model was designed for a location in southern Sweden.

The greenhouse has a high input of both heat and electricity for lighting, which combined with other factors gives a yearly yield of $84.4 \mathrm{~kg}$ tomato per $\mathrm{m}^{2}$. The greenhouse is estimated to generate $17 \mathrm{~kg} / \mathrm{m}^{2}$ year of continuous organic waste during the growing period. This amount was based on personal communication with a Swedish tomato grower (Peckas Naturodlingar AB, personal communication, April 8, 2021).

\section{Energy}

The results from the SIOM simulation software show that the greenhouse requires $12.5 \mathrm{MJ}$ of heat and 9.7 MJ of electricity per functional unit to maintain the desired indoor climate and amount of lighting (Danevad et al., 2021). This applies to both the reference system and the combined system. For the reference system it is assumed that heat is provided from combustion of wood chips (Bauer, 2019), which is the most common choice for tomato production in Sweden (Jordbruksverket, 2018), and the electricity is represented by the Swedish electricity mix (Treyer, 2019b).

Heat and electricity in the combined system is produced from biogas provided by the SS-AD plant, and it is assumed that a heat and power co-generation gas engine is used (Treyer, 2019a). The original dataset for the biogas was adapted to reflect the feedstock of the Forsbacka plant. Due to the high amount of electricity required, it is not possible to efficiently produce the whole amount locally, so $0.98 \mathrm{MJ}$ of the electricity is assumed to be Swedish electricity mix. It is also assumed that parts of the heat produced during the day is stored for use during the night.

\section{Organic Waste Treatment and Fertilizers}

Digestate in Sweden is mostly used as a biofertilizer, some of the biogas plants sell it but in amounts representing only a marginal part of the total volume produced (Ahlberg-Eliasson et al., 2017). It is then assumed that the digestate itself does not have an environmental impact.

The nutrient content in the digestate is directly dependent on the chemical characteristics of the feedstocks. In ORWARE, detailed information on the chemical components of the digestate can be followed by mass flow analysis, thus obtaining the specific values for each fraction of the digestate, liquid, and solid. Since the greenhouse is a hydroponic process, focus was paid only to the characteristics of the liquid fraction.

After the digestion process, most of the mineralized nitrogen in the digestate is in its reduced form, ammonium $\left(\mathrm{NH}_{4}^{+}\right)$, which can be used as a nitrogen source for fruit and vegetable production. However, higher concentrations of it can also be toxic to plants (Siddiqi et al., 2002). Specifically, tomato plants are highly sensitive to ammonia concentrations above roughly $10 \%$ of the total nitrogen, and it has been already established by many authors (Sonneveld and Voogt, 2009; Stoknes et al., 2018; Pelayo Lind et al., 2020) that a nitrification process is necessary when using digestate. It was then assumed that the liquid fraction of the digestate used as a nutrient solution went through a nitrification process with a conversion efficiency of $75 \%$ from ammonia to nitrate (Botheju et al., 2010), and a maximum dose of no more than $14 \mathrm{~g}$ ammonium per ton of nutrient solution, representing 9\% (Voogt, 1993; Strandmark, 2017). In that sense, ammonium is the limiting factor in the application of the nutrient solution. The calculation method is described in detail by Strandmark (2017). Due to lack of data, the nitrification process was included in the MFA calculations but not in the LCA calculations.

The yearly uptake of the major nutrients, nitrogen $(\mathrm{N})$, phosphorus (P), and potassium (K), for a $60 \mathrm{~kg} / \mathrm{m}^{2}$ of tomato yield are as follows (Sonneveld and Voogt, 2009): 1,185 kg N/ha, $284 \mathrm{~kg} \mathrm{P} / \mathrm{ha}$, and 2,044 kg K/ha. With these values, the nutrients necessary for the yield of this study, $84.4 \mathrm{~kg} / \mathrm{m}^{2}$, were calculated: 
$1.975 \mathrm{~g} \mathrm{~N} / \mathrm{FU}, 0.47 \mathrm{~g} \mathrm{P} / \mathrm{FU}$, and $3.4 \mathrm{~g} \mathrm{~K} / \mathrm{FU}$. For the reference system this amount will be covered with conventional fertilizers (EcoInvent, 2019a,b; Parada, 2019) while for the combined system it will be covered with the liquid digestate to the greatest degree.

In the reference system the TRW is assumed to be treated by industrial composting (Zschokke-Gohl, 2019a), while for the combined system it is treated by AD (Zschokke-Gohl, 2019b).

\section{Carbon Dioxide}

The greenhouse requires supplementation of $0.219 \mathrm{~kg}$ of $\mathrm{CO}_{2}$ per functional unit (Danevad et al., 2021). For the reference system, it was assumed that liquid carbon dioxide originates from a biorefinery in Norrköping, Sweden, where a major Swedish producer of carbon dioxide is located. In the combined system, it was assumed that the $\mathrm{CO}_{2}$ from the biogas produced in the $\mathrm{SS}-\mathrm{AD}$ is captured in parallel with the upgrading of the biogas through an amine scrubber, which is the applied technology in the Forsbacka plant, and the second most used in Sweden (Energimyndigheten, 2020). The amine scrubber has an efficiency of 99 vol\% for $\mathrm{CH}_{4}$ and 93 vol\% for $\mathrm{CO}_{2}$. The $\mathrm{CO}_{2}$ was assumed to be separated from the upgraded biogas that is intended for use in the transport sector, not the raw biogas that is used in the greenhouse for energy purposes.

However, due to lack of LCI data, the same liquid $\mathrm{CO}_{2}$ dataset (Hischier, 2019) was used for both the reference system and the combined system. The changes based on choice of $\mathrm{CO}_{2}$ source are therefore limited to differences in transport distance to the greenhouse. To better reflect the systems under study, the EcoInvent dataset was modified to use Swedish electricity mix instead of the European electricity in the original dataset.

\section{Greenhouse Construction and Operation}

Data for the greenhouse construction and operation were retrieved from a EcoInvent dataset for Dutch fresh grade tomatoes (Magaud, 2019). The information about construction and infrastructure uses global market data and includes load bearing structures, covering materials and the technical infrastructure of the greenhouse. The amounts per FU are dependent on the tomato yield $\left(\mathrm{kg} / \mathrm{m}^{2}\right)$, so the amounts were recalculated according to information in the EcoInvent documentation to better represent the higher yield in this study. The greenhouse construction is the same for both reference system and the combined system. Information about the operation includes the use and application of pesticides, stone wool, irrigation, planting, and production of tomato seedlings. The dataset also includes information about land use and emissions occurring inside the greenhouse, e.g., from use of fertilizer. This information was not recalculated in any way and were kept the same as in the original EcoInvent dataset for both reference system and the combined system.

\section{Transports}

As the greenhouse and the SS-AD plant are assumed to be situated close to each other, the transport distances of biogas, liquid $\mathrm{CO}_{2}$ and digestate were set to $20 \mathrm{~km}$. For the reference system, the transport of the liquid $\mathrm{CO}_{2}$ was set to $330 \mathrm{~km}$.
TABLE 3 | Results from the digestion in the SS-AD by using ORWARE.

\begin{tabular}{lcc}
\hline Parameter & Current SS-AD & SS-AD w/TRW \\
\hline Biomethane (MJ/treated waste $)$ & 3,641 & 3,609 \\
$\mathrm{CO}_{2}\left(\mathrm{~kg} / \mathrm{t}_{\text {treated waste }}\right)$ & 108 & 107 \\
Liquid fraction of digestate $\left(\mathrm{kg} / \mathrm{t}_{\text {treated waste }}\right)$ & 752 & 749 \\
Solid fraction of digestate $\left(\mathrm{kg} / \mathrm{t}_{\text {treated waste }}\right)$ & 345 & 353 \\
\hline
\end{tabular}

This represents the distance between the greenhouse and the biorefinery in Norrköping, Sweden. All the transports were represented by a EcoInvent dataset for unspecified European lorries (Valsasina, 2019).

The EcoInvent dataset for fresh grade tomatoes includes both on-farm transports and transports of fertilizer. The on-farm transports were left unmodified while the amount of fertilizer transports were modified to reflect the fertilizer quantities used in the reference and combined systems. All other transports that were included as parts of EcoInvent datasets were included without any modifications.

\section{Life Cycle Impact Assessment}

The impact assessment was performed using the CMLIA baseline V3.06 method. Included impact categories were global warming potential (GWP), acidification potential (AP), eutrophication potential (EP), photochemical oxidation potential (POCP), abiotic depletion (ADP), abiotic depletion of fossil fuels (ADP fossil), ozone depletion potential (ODP), terrestrial ecotoxicity potential (TETP), and human toxicity potential (HTP). The impact categories were selected based on being the most commonly used for life cycle assessments of tomato production (Torres Pineda et al., 2021).

\section{Sensitivity Analysis}

A sensitivity analysis was performed to understand the impact the amount of TRW has on quantity and quality of both biogas and digestate. The amount of TRW was increased by changing the size of the greenhouse from two to 20 hectares.

The sensitivity of the choice of electricity mix was tested by substituting the Swedish electricity mix with European electricity mix (EcoInvent, 2019c) for both systems. The changes were made specifically for the electricity used by the greenhouse and for electricity used for production of liquid $\mathrm{CO}_{2}$, as those are the parts of the system that are assumed to use Swedish electricity and where most of the electricity usage occurs.

\section{RESULTS AND DISCUSSION}

\section{Material Flow Analysis}

The biogas and digestate results presented in Table 3 were obtained in simulations using the modified ORWARE model to represent the plant in Forsbacka (Carlos-Pinedo et al., 2020). The results show that TRW of these amounts have a small impact on the SS-AD plant. The amount of biomethane per ton of treated waste decreases slightly due to the nutrient content of the TRW not being enough to produce significant amounts of biogas, 
TABLE 4 | Nutrient composition of the liquid digestate obtained in ORWARE.

\begin{tabular}{lcc}
\hline & \multicolumn{2}{c}{ Liquid fraction } \\
\cline { 2 - 3 } Component $\left(\mathbf{k g} / \mathbf{t}_{\text {treated waste }}\right)$ & Current SS-AD & SS-AD w/TRW \\
\hline C-tot biological & 37.9 & 37.9 \\
Total Nitrogen, $\mathrm{N}$-tot & 3.92 & 3.86 \\
Ammonium nitrogen $\mathrm{NH}_{3} / \mathrm{NH}_{4}^{+}-\mathrm{N}$ & 3.38 & 3.33 \\
Phosphorus, P-tot & 0.37 & 0.36 \\
Potassium, $\mathrm{K}$ & 1.69 & 1.67 \\
\hline
\end{tabular}

creating a dilution effect in the mix of waste. Both $\mathrm{CO}_{2}$ and liquid digestate have a small decrease, while the solid digestate has an increase possibly due to the lignocellulosic matter in the leaves that are not degraded.

While the SS-AD plant produces more than the amount needed to support the greenhouse with biomethane and $\mathrm{CO}_{2}$, the TRW itself only provides a small share of the resources. When taking the output differences of the SS-AD plant before and after introduction of TRW into account, only 1.5 and $5.7 \%$ of the biomethane and $\mathrm{CO}_{2}$ required by the greenhouse can be covered. These results could change if other data sources were used for the chemical characteristics of TRW and other feedstocks. The ORWARE model is dependent on the nutrient content of the feedstocks, e.g., carbohydrates, lipids, and proteins, so the choice of data sources is important for the systems analysis. However, the leaves in the TRW are a relatively homogeneous waste, so for this case study the variations should be minor. Nutrient content in the liquid fraction of the digestate are listed in Table 4. The use of TRW in the SS-AD system had only a minor impact on the chemical characteristics of the digestate. From the analysis of the digestate, and assuming that the ammonium is the limiting factor in its application, we can substitute $100 \%$ of $\mathrm{N}, 45 \%$ of $\mathrm{P}$, and $29 \%$ of K when using TRW. The rest needs to be complemented with conventional fertilizers. These results were based on the method described by Strandmark (2017) and the assumption of a $75 \%$ nitrification conversion efficiency. A higher or lower efficiency would influence the amount of conventional fertilizers that could be replaced, which would affect these percentages and the LCA results.

\section{Life Cycle Assessment}

The LCA results for both the reference system and the combined system are shown in Table 5. The combined system consistently performs better than the reference system. A table with results for all the sub-systems can be found in the Supplementary Material.

Figure 2 visualizes the results of the life cycle assessment for both the reference system and the combined system. Several areas have an identical impact for both systems, as they were assumed to be identical, but they are included to visualize what importance the changing parts have for each impact category. The differences between the systems are very small for ADP, as most of the impact comes from the greenhouse construction, but for the other impact categories, it is clear that the combined system has a better environmental performance. The reason for this is mainly due to the lower impact per unit of energy. The impact from heat is lower for the combined system for all categories due to the low emissions and resource use from the biogas. Electricity usage in the combined system also has a lower environmental impact for all categories, with the exception of acidification potential due to emissions of sulfur dioxide. These emissions are caused by the sulfur content of the biogas, which is dependent on the characteristics of the feedstocks used in the SS-AD plant. Another reason that the combined system performs better is the use of digestate, which limits the amount of conventional fertilizers required.

Something worth noting is that emissions from the nitrification process were not included in the calculations. Treatment and handling of the digestate can generate emissions (Chiew et al., 2015; Stoknes et al., 2016). In particular, nitrous oxide $\left(\mathrm{N}_{2} \mathrm{O}\right)$ is emitted during the nitrification of ammonia (Rehl and Müller, 2011). Also, the impacts from the application of conventional and digestate fertilizers were assumed the same in both systems, while in reality there could be differences that affect this result.

The impact from the production of liquid $\mathrm{CO}_{2}$ is high for several categories, especially for ADP (fossil), GWP and HTP. The main reasons for the high contribution differs between the categories. For ADP (fossil), the main reason is the use of heat, where some natural gas is assumed to be used. For GWP, the main contributor is air emissions of methane, while for HTP almost the entire impact comes from the infrastructure and inputs of monoethanolamine. However, as the same LCI dataset was used for $\mathrm{CO}_{2}$ in both cases, there are no differences between the systems.

While the transports make out a small part of the total impact, it is clear that their impacts are lower for the combined system. The distance between SS-AD plant and greenhouse was assumed to be $20 \mathrm{~km}$, so it could be possible to decrease these numbers further by placing the SS-AD plant and the greenhouse at the same location.

\section{Sensitivity Analysis Material Flow Analysis}

Table 6 presents how the quality and quantity of biogas (including $\mathrm{CO}_{2}$ ) and digestate are affected if the SS-AD plant received TRW from a 20 ha greenhouse instead. The results show that the amount of biomethane produced per treated ton is $7.6 \%$ less than if no TRW was used. The amount of $\mathrm{CO}_{2}$ increases by $9 \%$, liquid digestate increases by $13 \%$, and solid digestate increases by $39 \%$. Evaluation of the quality of the liquid digestate shows that total carbon decreases by $0.5 \%$, total nitrogen decreases by $12.7 \%$, ammonium nitrogen decreases by $12 \%$, phosphorus decreased by $19 \%$, and potassium decreased by $6.5 \%$.

\section{Life Cycle Assessment}

Figure 3 shows the effect on the systems if European electricity is used instead of the Swedish electricity mix. While this change led to increased environmental impact for all categories in both systems, the increase was most substantial for the reference system since all the electricity comes from the electricity grid. 
TABLE 5 | Environmental impact of the systems.

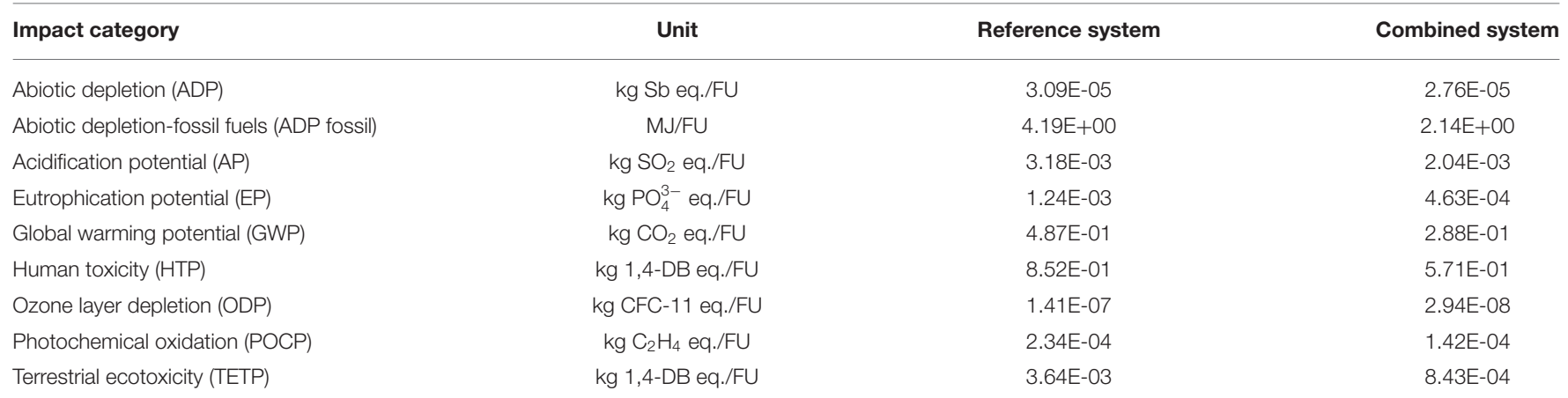

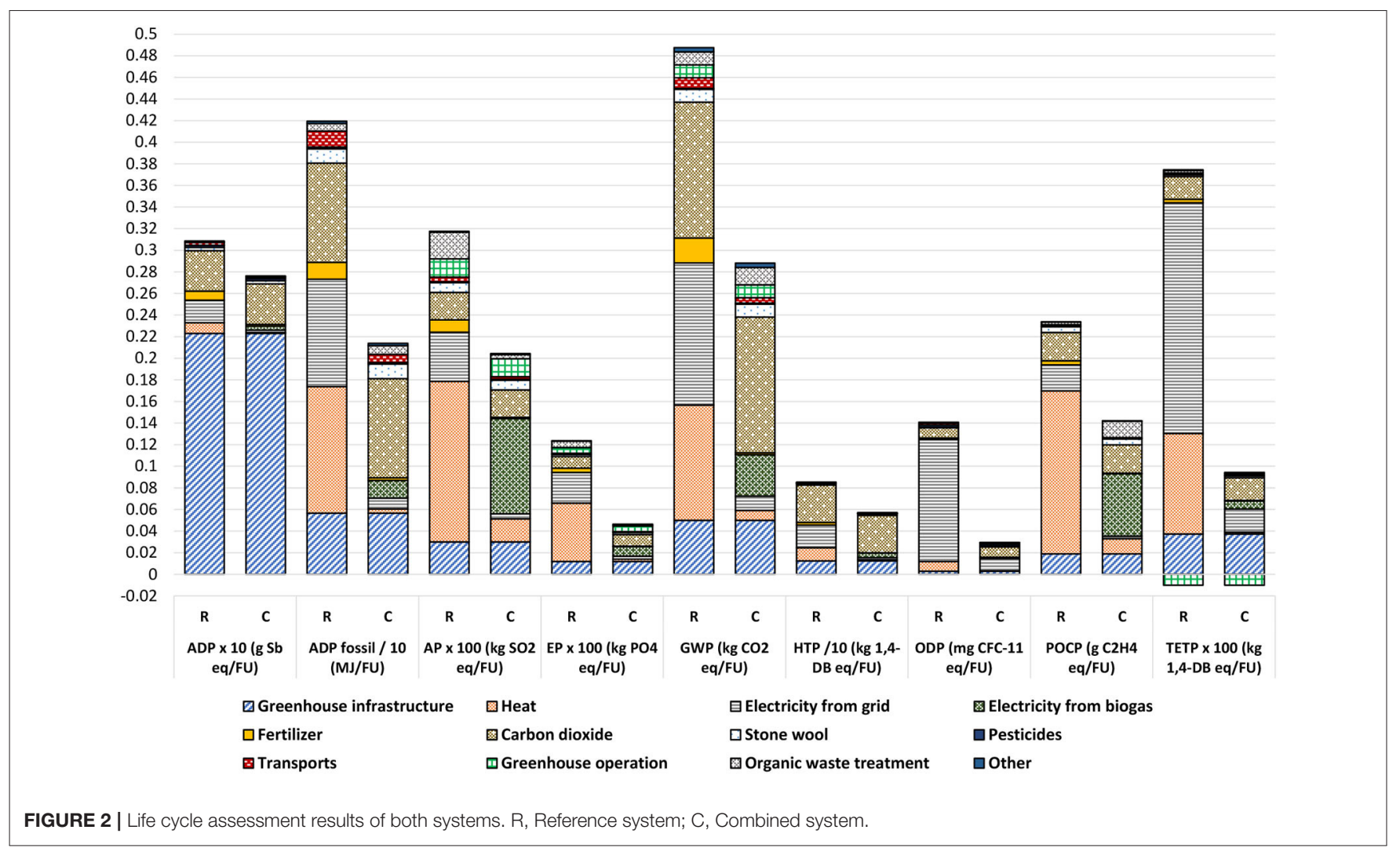

TABLE 6 | Implications of a TRW increase, greenhouse size increased to 20 ha.

\begin{tabular}{lccr}
\hline Digestion process & & Characteristics of the liquid fraction of digestate $\left(\mathbf{k g} / \mathrm{t}_{\text {treated }}\right.$ waste $)$ \\
\hline Tomato leaves (t/year) & 3,400 & C-tot biological & 37.7 \\
Biomethane $\left(\mathrm{MJ} / \mathrm{t}_{\text {treated waste }}\right)$ & 3,362 & Total Nitrogen, $\mathrm{N}$-tot & 3.42 \\
$\mathrm{CO}_{2}\left(\mathrm{~kg} / \mathrm{t}_{\text {treated }}\right.$ waste & 101 & Ammonium nitrogen $\mathrm{NH}_{3} / \mathrm{NH}_{4}^{+}-\mathrm{N}$ & 2.97 \\
Liquid fraction of digestate $\left(\mathrm{kg} / \mathrm{t}_{\text {treated waste }}\right)$ & 731 & Phosphorus, $\mathrm{P}$-tot & 0.30 \\
Solid fraction of digestate $\left(\mathrm{kg} / \mathrm{t}_{\text {treated waste }}\right)$ & 413 & Potassium, $\mathrm{K}$ & 1.58
\end{tabular}




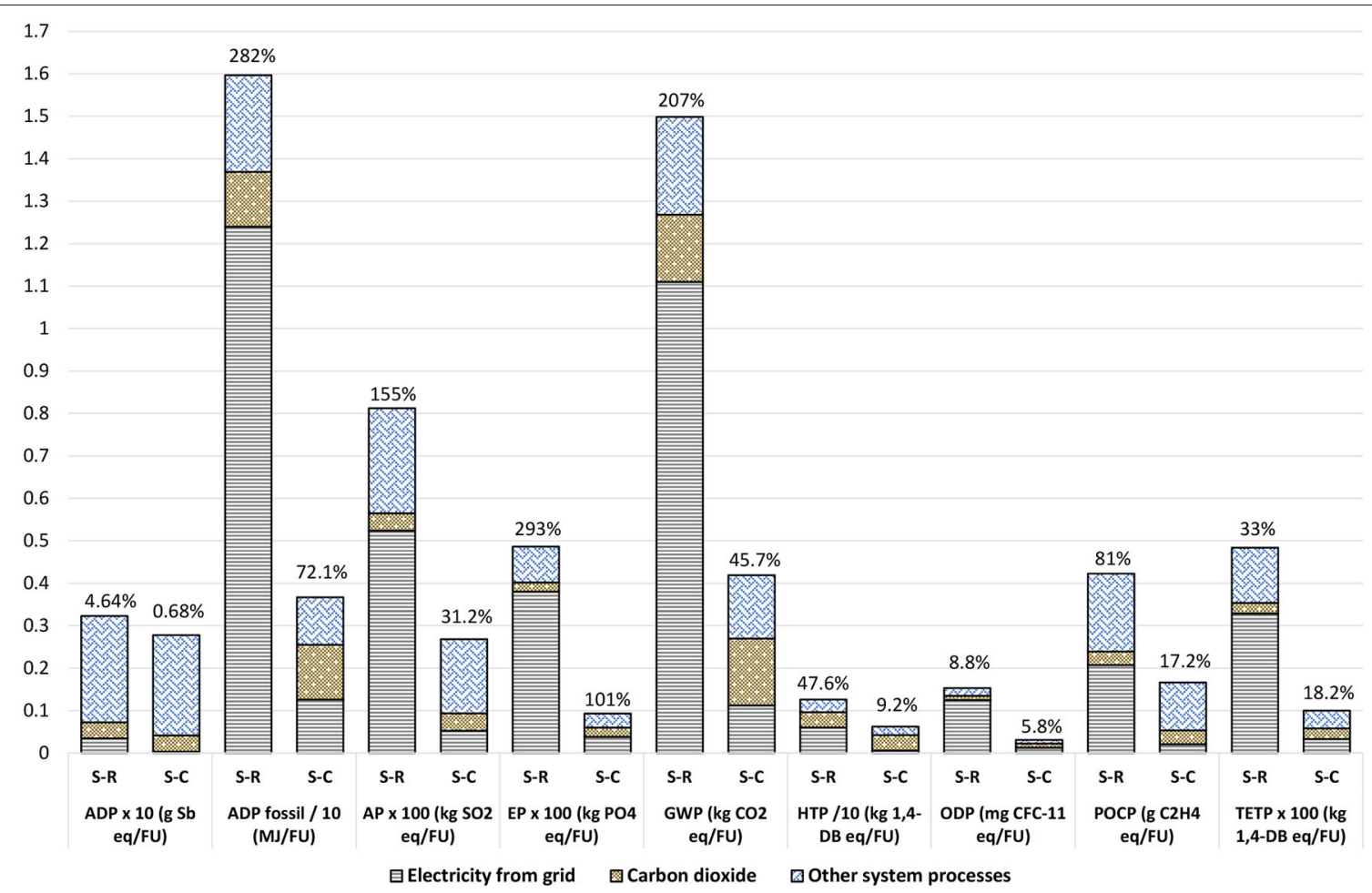

FIGURE 3 | Effects of using European electricity instead of Swedish electricity. Percentages represent the increase of environmental impact relative to the original systems.

This shows that the electricity chosen during the LCA modeling plays an important role for the results, especially in this case since the greenhouse uses high amounts of electricity.

\section{CONCLUSIONS}

This research fills a literature gap when it comes to evaluation of the environmental implications of interconnecting the inputs and outputs between a greenhouse and an SS-AD plant. Countries and regions with similar conditions as those described in this study should be able to use the material and results of this study as a part of an evaluation process when deciding on future system designs.

The results of the MFA shows that the amounts of biomethane and $\mathrm{CO}_{2}$ produced by the SS-AD plant are enough to support the greenhouse when also using resources from other feedstocks than TRW. The TRW itself is only enough for providing $1.5 \%$ of the biomethane and $5.7 \%$ of the $\mathrm{CO}_{2}$ required by the greenhouse. When the TRW is added, the amounts of liquid digestate per unit of treated waste increases. However, the nutrient content per unit of digestate decreases for all evaluated nutrients.

The LCA results clearly show that using biogas and digestate from an SS-AD process in a greenhouse plant can drastically improve the potential environmental impact of the greenhouse compared to the option of operating on wood chips and using electricity from the Swedish electricity grid. This is mainly due to a lower environmental impact per unit of energy that is used. In addition, replacing a portion of the conventional fertilizers with digestate contributes with lowering the impact further.

- The abiotic depletion potential is mainly caused by greenhouse infrastructure and the differences are small between reference system and the combined system $\left(3.09 \times 10^{-2}\right.$ and $2.76 \times$ $10^{-2} \mathrm{~g}$ Sb-eq./FU, respectively).

- The fossil abiotic depletion potential has a substantial difference that mainly comes from the reference system using larger amounts of fossil fuels in the background processes for heat and electricity ( 4.19 and $2.14 \mathrm{MJ} / \mathrm{FU})$.

- The difference for acidification potential in large parts stems from higher nitrogen oxide emissions from heat generation in the reference system. The combined system does have a higher impact for electricity due to higher emissions of sulfur dioxide during combustion of the biogas, but the reference system still has a higher overall impact ( 3.18 and $2.04 \mathrm{~g} \mathrm{SO}_{2}$-eq./FU).

- The reference system has a higher eutrophication potential than the combined system due to higher emissions from both heat and electricity, mainly from emissions of phosphate and nitrogen oxides (1.24 and $0.463 \mathrm{~g} \mathrm{PO}_{4}^{3-}$-eq./FU).

- The global warming potential for the reference system is higher than for the combined system mainly due to emissions from heat and electricity generation $\left(487\right.$ and $288 \mathrm{~g} \mathrm{CO}_{2-}$ eq./FU).

- The human toxicity potential is also lower for the combined system. The reason is mainly due to a lower impact per unit of energy (852 and $571 \mathrm{~g} 1,4$-DB-eq). 
- The ozone depletion potential of the reference system comes almost entirely from the electricity usage. The combined system uses very little electricity from the grid and therefore has a much lower ozone depletion potential $\left(1.41 \times 10^{-4}\right.$ and $2.94 \times 10^{-5}$ g CFC-11-eq./FU).

- For photochemical oxidation potential, the heat is the main contributor for the reference system while electricity is a major contributor for the combined system. Overall, the reference system has a higher environmental impact, in large part due to carbon monoxide emissions from the heat production. Most of the non-energy areas are roughly the same (0.234 and $0.142 \mathrm{~g} \mathrm{C}_{2} \mathrm{H}_{4}$-eq./FU).

- For terrestrial ecotoxicity potential, the impact is higher for the reference system mainly due to a much higher impact per unit of electricity (3.64 and $0.843 \mathrm{~g}$ 1,4-DBeq./FU).

\section{DATA AVAILABILITY STATEMENT}

The original contributions presented in the study are included in the article/Supplementary Material, further inquiries can be directed to the corresponding author.

\section{REFERENCES}

Ahlberg-Eliasson, K., Nadeau, E., Levén, L., and Schnürer, A. (2017). Production efficiency of Swedish farm-scale biogas plants. Biomass Bioenergy 97, 27-37. doi: 10.1016/j.biombioe.2016.12.002

Arizpe, N., Giampietro, M., and Ramos-Martin, J. (2011). Food security and fossil energy dependence: an international comparison of the use of fossil energy in agriculture (1991-2003). CRC. Crit. Rev. Plant Sci. 30, 45-63. doi: 10.1080/07352689.2011.554352

Bauer, C. (2019). Heat Production, Softwood Chips From Forest, at Furnace $1000 \mathrm{~kW}$, State-of-the-Art, ROW, Allocation, Cut-Off by Classification. Ecoinvent Database Version 3.6.

Bergstrand, K. J., Asp, H., and Hultberg, M. (2020). Utilizing anaerobic digestates as nutrient solutions in hydroponic production systems. Sustain 12, 1-12. doi: $10.3390 /$ su122310076

Botheju, D., Svalheim, O., and Bakke, R. (2010). Digestate nitrification for nutrient recovery. Open Waste Manag. J. 3, 1-12. doi: 10.2174/1876400201003010001

Burg, V., Golzar, F., Bowman, G., Hellweg, S., and Roshandel, R. (2021). Symbiosis opportunities between food and energy system: the potential of manure-based biogas as heating source for greenhouse production. J. Ind. Ecol. 25, 648-662. doi: $10.1111 /$ jiec. 13078

Carlos-Pinedo, S., Wang, Z., Eriksson, O., and Soam, S. (2020). Study of the digestion process at a full-scale solid-state biogas plant by using ORWARE: model modification and implementation. Waste Manag. 107, 133-142. doi: 10.1016/j.wasman.2020.03.036

Chiew, Y. L., Spångberg, J., Baky, A., Hansson, P. A., and Jönsson, H. (2015). Environmental impact of recycling digested food waste as a fertilizer in agriculture - a case study. Resour. Conserv. Recycl. 95, 1-14. doi: 10.1016/j.resconrec.2014.11.015

Danevad, D., Sapounas, A., Hillman, K., and Eriksson, O. (2021). Life Cycle Assessment of Greenhouse Tomatoes for the Swedish Market [Unpublished Manuscript, to be Submitted].

Dorais, M., and Dubé, Y. (2011). Managing greenhouse organic wastes: a holistic approach. Acta Hortic. 893, 183-198. doi: 10.17660/ActaHortic.2011. 893.12

EcoInvent (2019a). Market for Nitrogen Fertiliser, as N, GLO, Allocation, Cut-Off by Classification. Ecoinvent database version 3.6.

\section{AUTHOR CONTRIBUTIONS}

All authors have contributed equally to study design, data collection, analysis, and writing of the paper.

\section{FUNDING}

This work was supported by Gävle Energi $A B$, Gästrike Återvinnare Utveckling $\mathrm{AB}$ and the research foundation Gästrikeregionens miljö.

\section{ACKNOWLEDGMENTS}

We wish to show our appreciation to Karl Hillman, Ola Eriksson, Shveta Soam, and Zhao Wang at the University of Gävle, for help and guidance during the completion of this work.

\section{SUPPLEMENTARY MATERIAL}

The Supplementary Material for this article can be found online at: https://www.frontiersin.org/articles/10.3389/frsus. 2021.770296/full\#supplementary-material

EcoInvent (2019b). Market for Phosphate Fertiliser, as P2O5, GLO, Allocation, Cut-Off by Classification. Ecoinvent database version 3.6.

EcoInvent (2019c). Market Group for Electricity, Medium Voltage, RER, Allocation, Cut-Off by Classification. Ecoinvent database version 3.6.

Energigas Sverige (2021). Statistik om biogas. Available online at: https://www. energigas.se/fakta-om-gas/biogas/statistik-om-biogas/ (accessed November $25,2021)$.

Energimyndigheten (2020). Produktion och användning av biogas och rötrester år 2019 [Production and Use of Biogas and Digestate Year 2019]. Available online at: https://energimyndigheten.a-w2m.se/Home.mvc?ResourceId=179401

Eriksson, O., Frostell, B., Assefa, G., Granath, J., Carlsson, M., Baky, A., et al. (2002). ORWARE - a simulation tool for waste management keywords. Resour. Conserv. Recycl. 36, 287-307. doi: 10.1016/S0921-3449(02)00031-9

Gävle Energi (2018). Cirkulära kretslopp: Slutrapport [Circular Ecocycles: Final Report]. Gävle.

Hischier, R. (2019). Carbon Dioxide Production, Liquid, RER, Allocation, Cut-off by Classification. Ecoinvent database version 3.6.

IPCC (2018). Summary for policymakers. In: Masson-Delmotte V, Zhai P, Pörtner H-O, Robergs D, Skea J, Shukla PR, et al., editors. Global Warming of $1.5^{\circ} \mathrm{C}$. Geneva: World Meteorological Organization, 1-24.

Jordbruksverket (2018). Energianvändning i växthus 2017 Statistikrapport 2018:05 [Energy Use in Greenhouses 2017 Statistics Report 2018:05]. Available online at: https://jordbruksverket.se/download/18.341a6d7171e33d0f42d4985/ 1588860072873/201805.pdf

Jordbruksverket (2020). Svensk handel med jordbruksvaror och livsmedel 2019 [Swedish Trade With Agricultural Products and Food 2019]. Available online at: https://jordbruksverket.se/download/18.28f4d91b172cdd65219e8c80/ 1592810013783/På tal om jordbruk och fiske Handelsutveckling 2019.pdf

Magaud, V. (2019). Tomato Production, Fresh Grade, in Heated Greenhouse, NL, Allocation, Cut-Off by Classification. Ecoinvent database version 3.6.

Martin, M., Poulikidou, S., and Molin, E. (2019). Exploring the environmental performance of urban symbiosis for vertical hydroponic farming. Sustain 11, 10-12. doi: 10.3390/su11236724

Menardo, S., Bauer, A., Theuretzbacher, F., Piringer, G., Nilsen, P. J., Balsari, P., et al. (2013). Biogas production from steam-exploded miscanthus and utilization of biogas energy and $\mathrm{CO}_{2}$ in greenhouses. Bioenergy Res. 6, 620-630. doi: $10.1007 / \mathrm{s} 12155-012-9280-5$ 
Neves, A., Godina, R., Azevedo, S. G., and Matias, J. C. O. (2020). A comprehensive review of industrial symbiosis. J. Clean. Prod. 247. doi: 10.1016/j.jclepro.2019.119113

Parada, S. (2019). Market for Potassium Fertiliser, as K2O, GLO, Allocation, Cut-Off by Classification. Ecoinvent Database Version 3.6.

Pelayo Lind, O., Hultberg, M., Bergstrand, K. J., Larsson-Jönsson, H., Caspersen, S., and Asp, H. (2020). Biogas digestate in vegetable hydroponic production: $\mathrm{pH}$ dynamics and $\mathrm{pH}$ management by controlled nitrification. Waste Biomass Valorization. 12, 123-33. doi: 10.1007/s12649-020-00965-y

Poore, J., and Nemecek, T. (2018). Reducing food's environmental impacts through producers and consumers. Science 360, 987-992. doi: 10.1126/science.aaq0216

Rehl, T., and Müller, J. (2011). Life cycle assessment of biogas digestate processing technologies. Resour. Conserv. Recycl. 56, 92-104. doi: 10.1016/j.resconrec.2011.08.007

Sendra, C., Gabarrell, X., and Vicent, T. (2007). Material flow analysis adapted to an industrial area. J. Clean. Prod. 15, 1706-1715. doi: 10.1016/j.jclepro.2006.08.019

Siddiqi, M. Y., Malhotra, B., Min, X., and Glass, A. D. M. (2002). Effects of ammonium and inorganic carbon enrichment on growth and yield of a hydroponic tomato crop. J. Plant Nutr. Soil Sci. 165, 191-197. doi: 10.1002/ 1522-2624(200204)165:2<191::AID-JPLN191>3.0.CO;2-D

Sonneveld, C., and Voogt, W. (2009). Plant Nutrition of Greenhouse Crops. Dordrecht: Springer.

Stoknes, K., Scholwin, F., Krzesiński, W., Wojciechowska, E., and Jasińska, A. (2016). Efficiency of a novel "Food to waste to food" system including anaerobic digestion of food waste and cultivation of vegetables on digestate in a bubble-insulated greenhouse. Waste Manag. 56, 466-476. doi: 10.1016/j.wasman.2016.06.027

Stoknes, K., Wojciechowska, E., Jasińska, A., Gulliksen, A., and Tesfamichæl, A. A. (2018). Growing vegetables in the circular economy; cultivation of tomatoes on green waste compost and food waste digestate. Acta Hortic. 1215, 389-396. doi: 10.17660/ActaHortic.2018.1215.71

Strandmark, E. (2017). Biogödsel som kvävekälla i hydroponisk tomatproduktion [Biodigestate as a Nitrogen Source in Hydroponic Tomato Production]. Available online at: https://stud.epsilon.slu.se/10164/

TNO (2021). SIOM: Systems Integration for International Greenhouse Horticulture. Available online at: https://www.tno.nl/en/focus-areas/buildingsinfrastructure-maritime/roadmaps/buildings-infrastructure/greenhousedesign/systems-integration-for-international-greenhouse-horticulture/ (accessed February 1, 2021).

Torres Pineda, I., Lee, Y. D., Kim, Y. S., Lee, S. M., and Park, K. S. (2021). Review of inventory data in life cycle assessment applied in production of fresh tomato in greenhouse. J. Clean. Prod. 282:124395. doi: 10.1016/j.jclepro.2020. 124395

Treyer, K. (2019a). Heat and Power Co-Generation, Biogas, Gas Engine, SE, Allocation, cut-Off by Classification. Ecoinvent database version 3.6.
Treyer, K. (2019b). Market for Electricity, Medium Voltage, SE, Allocation, Cut-Off by Classification. Ecoinvent database version 3.6.

Valsasina, L. (2019). Market for Transport, Freight, Lorry, Unspecified, RER, Allocation, Cut-Off by Classification. Ecoinvent database version 3.6.

Venkata Sreeharsha, R., and Venkata Mohan, S. (2021). Symbiotic integration of bioprocesses to design a self-sustainable life supporting ecosystem in a circular economy framework. Bioresour. Technol. 326:124712. doi: 10.1016/j.biortech.2021.1 24712

Voogt, W. (1993). Nutrient uptake of year round tomato crops. Acta Hortic. 339, 99-112. doi: 10.17660/ActaHortic.199 3.339 .9

Wallin, C. J. (2020). A Study of Infrastructure and Energy Use in Swedish Industrial Greenhouses. Available online at: http://www.diva-portal.org/smash/record.jsf? pid=diva2\%3A1477237\&dswid=-9544.

Wernet, G., Bauer, C., Steubing, B., Reinhard, J., Moreno-Ruiz, E., and Weidema, B. (2016). The ecoinvent database version 3 (part I): overview and methodology. Int. J. Life Cycle Assess. 21, 1218-1230. doi: 10.1007/s11367-016-1087-8

Yang, L., Xu, F., Ge, X., and Li, Y. (2015). Challenges and strategies for solid-state anaerobic digestion of lignocellulosic biomass. Renew. Sustain. Energy Rev. 44, 824-834. doi: 10.1016/j.rser.2015.01.002

Zschokke-Gohl, M. (2019a). Treatment of Biowaste, Industrial Composting, RoW, Allocation, Cut-Off by Classification. Ecoinvent database version 3.6.

Zschokke-Gohl, M. (2019b). Treatment of Biowaste by Anaerobic Digestion, RoW, Allocation, Cut-Off by Classification. Ecoinvent database version 3.6.

Conflict of Interest: The authors declare that the research was conducted in the absence of any commercial or financial relationships that could be construed as a potential conflict of interest.

Publisher's Note: All claims expressed in this article are solely those of the authors and do not necessarily represent those of their affiliated organizations, or those of the publisher, the editors and the reviewers. Any product that may be evaluated in this article, or claim that may be made by its manufacturer, is not guaranteed or endorsed by the publisher.

Copyright (C) 2021 Danevad and Carlos-Pinedo. This is an open-access article distributed under the terms of the Creative Commons Attribution License (CC BY). The use, distribution or reproduction in other forums is permitted, provided the original author(s) and the copyright owner(s) are credited and that the original publication in this journal is cited, in accordance with accepted academic practice. No use, distribution or reproduction is permitted which does not comply with these terms. 